\title{
The Analysis of the Influence and Inspiration of the Bauhaus on Contemporary Design and Education
}

\author{
Wenwen $\mathrm{Chen}^{1 *}$, Zhuozuo $\mathrm{He}^{2}$ \\ ${ }^{1}$ Shanghai University of Engineering Science, Shanghai, China \\ ${ }^{2}$ Zhongyuan University of Technology, Zhengzhou, China \\ Email: "cadidl@hotmail.com
}

Received October 11, 2012; revised February 24, 2013; accepted March 2, 2013

Copyright (c) 2013 Wenwen Chen, Zhuozuo He. This is an open access article distributed under the Creative Commons Attribution License, which permits unrestricted use, distribution, and reproduction in any medium, provided the original work is properly cited.

\begin{abstract}
The Bauhaus, one of the most prestigious colleges of fine arts, was founded in 1919 by the architect Walter Gropius. Although it is closed in the last century, its influence is still manifested in design industries now and will continue to spread its principles to designers and artists. Even, it has a profound influence upon subsequent developments in art, architecture, graphic design, interior design, fashion design and design education. Up until now, Bauhaus ideal has always been a controversial focus that plays a crucial role in the field of design. Not only emphasizing function but also reflecting the human-oriented idea could be the greatest progress on modern design and manufacturing. Even more, harmonizing the relationship between nature and human is the ultimate goal for all the designers to create their artworks. This essay will analyze Bauhaus's influence on modern design and manufacturing in terms of technology, architecture and design education.
\end{abstract}

Keywords: The Bauhaus School; Functionalism; Modernism; Crossover Design; Art Education

\section{Introduction}

The Bauhaus, one of the most prestigious colleges of fine arts, was founded in 1919 by the architect Walter Gropius. It consisted the school of Arts and the school of Crafts, which were closed for the duration of the war and renamed Staatliches Bauhaus Weimar to State Bauhaus Weimar. Due to conflicts with the National Socialists, on April 1925, the Bauhaus institute moved to Dessau from Weimar [1]. From 1932 to 1933, the local Dessau legislative body had to move their college to Berlin, as a private institution. After being occupied by the police and a contingent of storm-troopers, the director announced the closure of the Bauhaus. Up until now, Bauhaus has always been a controversial focus that played a crucial role in the field of design. This essay will analyze Bauhaus's influence on modern design and manufacturing in terms of technology, architecture and art education.

\section{Technology}

To interweave arts and technology is not the only principle of Bauhaus. The meaning of the word "Bauhaus" is clear evidence. In Germany, "bau" refers to building and

${ }^{*}$ Corresponding author. "haus" means house, symbolising that art and technology should be composed together in design field. In 1923, the director Walter Gropius introduced reconciliation between "creative artists and the industrial world" [2], which changed the focus of design theories from aesthetics to practicality. When the industrial revolution began, traditional skilled craftsmen were gradually replaced by machines while reducing cost through mass-production eroded aesthetic standards [3]. Thus, William Morris thought it dishonest for machine-made goods to pretend to be hand-made, while John Ruskin went further in his belief that the machine itself was a source of evil and social ills. Due to the fact that design was separated from manufacturing, it enhanced the independence of design. "The traditional craftsman who both conceived and manufactured his products had to be replaced by someone who conceived and described what would be produced by others with the aid of the machine: a designer" [4]. It reflected that artists did not concentrate on commodity design during that period, which made the contradiction between art and technology obvious. The stereotyped industrial products without a design sense and handicrafts cannot meet the social needs.

At the end of the nineteenth century, compared with the concept "civilization", Germany values the develop- 
ment of culture more. It leads to seek culture identity and also contribute to the formation and development of Bauhaus. At the beginning of 20th centuries, many art organizations in Germany have strong desire to look for Deutsche style. They explore it in many fields: those retro and luxury style, superfluous or tasteless embellishment in architecture, or massive unreasonable machineries like the Rococo spinner have caused intensification of contradictions. Then architect Walter Gropius revolutionized design theories by emphasizing products' functionalities over appearances, stimulating the development of modern design theory. He emphasized multiple criteria which include constructing design structure reasonably, selecting materials appropriately and presenting the making process clearly. For example, a series of metal tea vessel, ashtray and desk lamp designed by Marianne Brandt have high rational characteristic. Simple modernist style reflected intact, no extra fancy decoration, excellent function expression and simple shapes.

Additionally, Bauhaus to some extent constructed unity between arts and technology. Bauhaus promoted the technological innovation by means of new materials and structures, for example, some European countries had potential of using iron and glass to make the buildings as if it was built in the mid-19th century [5]. The international style building, the Villa Savoye, which used steel and concrete and wooden skeletons as walls no longer sustain the whole building implies that modern architecture design could also connect with technology innovation [6]. Bauhaus had great impacts in the field of design, as it influenced our current contemporary society to explore multi-functional, high quality materials that stimulate market with more competitive capability. Bauhaus's principle on combining arts with technology will continue to enhance values of products.

Nowadays, the interpretation of Bauhaus slogan "Art and Technology in a New Unity" evolves crossover design. Crossover design refers to cooperate and interact with same design concept in various fields. By means of various industrial technology, it will transform multiform products. For instance, the Dutch De Stijl artist Piet Mondrian emphasis the geometry with vertical and parallel lines display the purest color appropriately, manifesting material and spiritual balance as well. His artwork was created in 1930, an oil painting named "Composition II in Red, Blue, and Yellow", which inspire the Bauhaus students and modern designer interpreting into various products: pencil box, fashion, shoes, bicycles and watch (Figure 1). The unity of art and technology arouses contemporary designers to get rid of their professional limitations, but more meet the need of the time.

\section{Architecture}

Moreover, Henry van de Velde, a prominent architect,
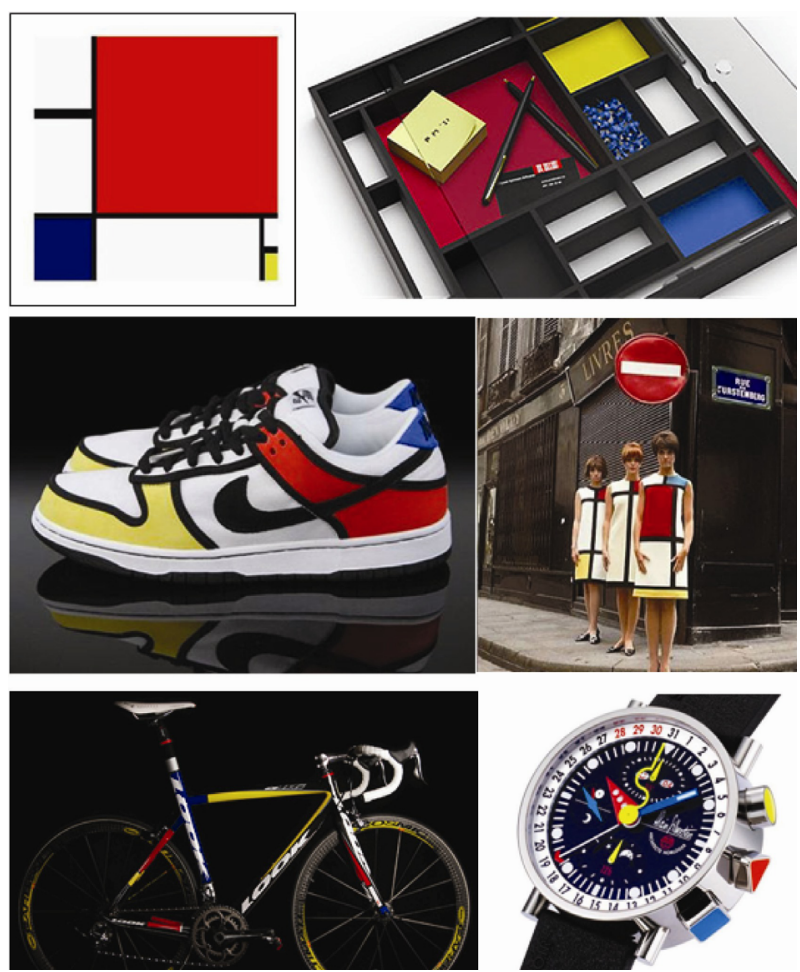

Figure 1. Crossover design from Piet Mondrian's inspiration [7].

designer and painter, discovered the similarity in work between the engineer-architects and the designers' new products. He suggested that "The Forms reflected the function”, especially in terms of new materials [8]. Velde's idea gave birth to the new standards of beauty. By comparing the Bauhaus Dessau buildings with traditional architectures, the advantages of function can be easily seen. Instead of applying the contemporary symmetric principle, the new Bauhaus building (Figure 2) adept flexible, irregular layout such as more aisles and directions, approaching to the principle of Modernismless is more.

To some extent, Minimalism, which was popular during 1950's, has inherited the Bauhaus' spirit. In Walter Gropius's book The new architecture and the Bauhaus, he points out that "Instead of anchoring buildings ponderously into the ground with massive foundations, it poises them lightly, yet firmly, upon the face of the earth; and bodies itself forth, not in stylistic imitation or ornamental frippery, but in those simple and sharply modeled designs in which every part merges naturally into the comprehensive volume of the whole. Thus its aesthetic meets our material and psychological requirements alike" [10]. Barcelona Pavilion and Seagram Building in New York City designed by Mies van der Rohe would serve as two perfect evidence of modernism design (Figures 3 and 4). This building is a luxury and extraordinary office building located in Manhattan. Besides the elevator sites, 


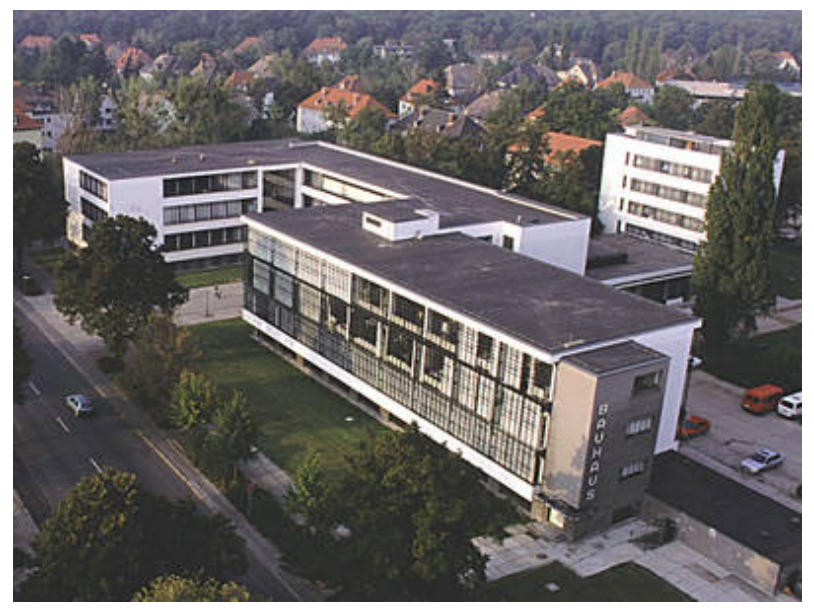

Figure 2. The Bauhaus building [9].
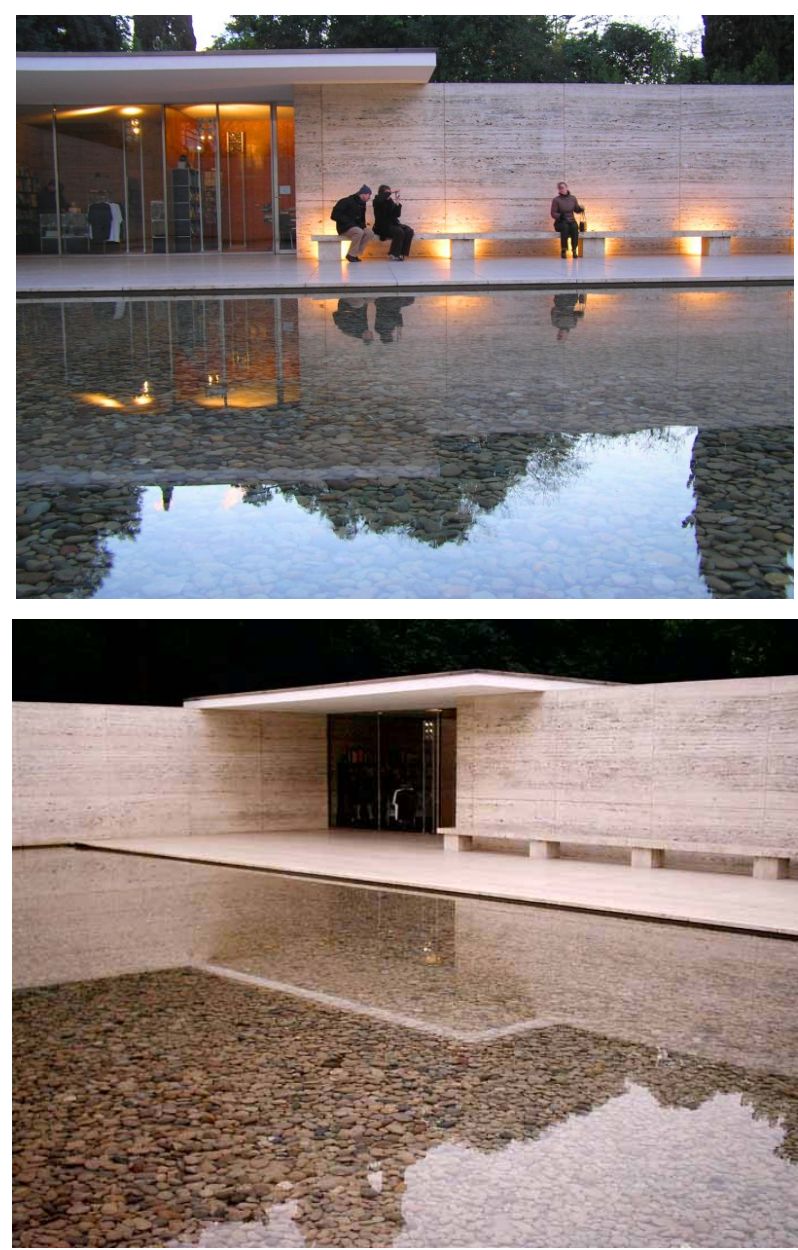

Figure 3. Barcelona Pavilion [11].

there is an open space on the ground floor with easy transportation. It looks like a regular hexahedron, demonstrating modern materials of steel and glass, fully displaying the design principle "less is more". Similarly, Barcelona Pavilion is regarded as German interpretation and aesthetics of modernism construction. In terms of
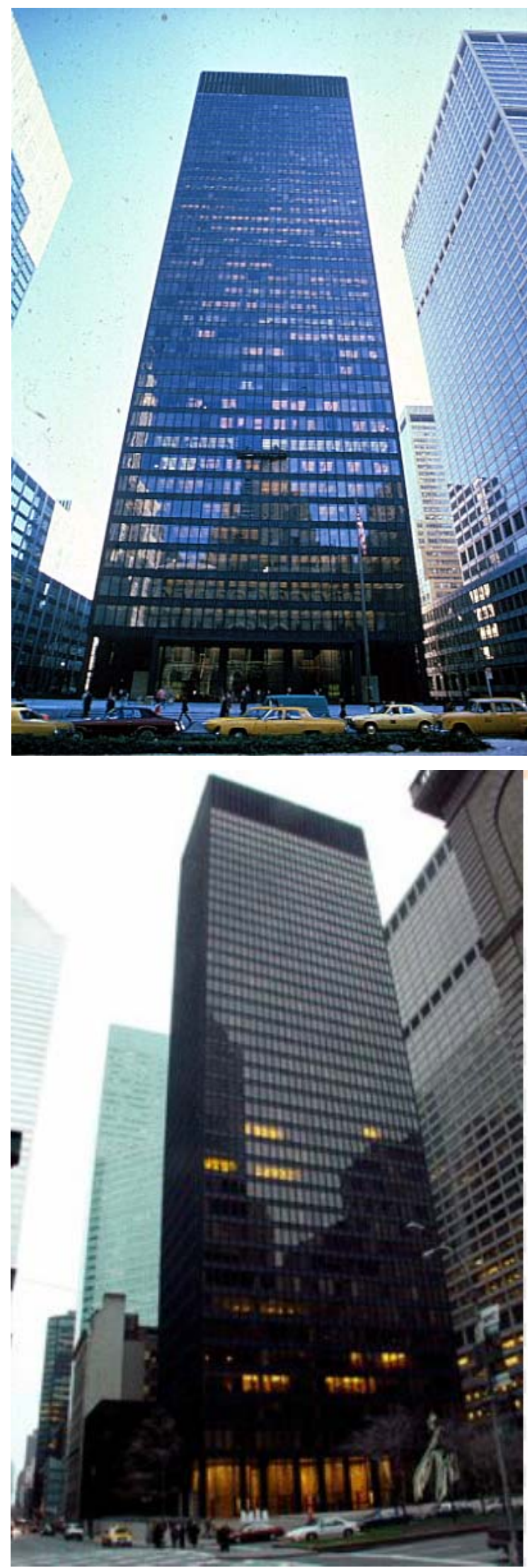

Figure 4. Seagram Building in New York City [12]. 
space distribution and bearing structure, it breaks the concept of room. Those pillars connected ceiling directly enlarge the space, whose inspiration comes from Cubism painting, reflecting more consideration between physical demand and social needs. Germany design is calm, highly rational, and also human-orientated.

"The Villa Savoye" designed by Le Corbusier, is a classic example to represent International Style, due to its new frame structure (Figure 5). Those strip windows, flat roof and deck area are the most important parts to make up its apparent simplicity. In Figure 5, the first floor of the Villa Savoye extends beyond the base, which makes the structure seem to hover in mid air. Several geometric concepts are adopted in the design. Glass windows and geometric structure are also correspondent to the characters of modern architectures. The interior design demonstrates a Purist style such as the smooth white surface, built with reinforced concrete, without ornaments. Functionalities were complimented by its simplicity. In terms of contemporary industrial design, this principle had been used widely from tableware to furniture. Apprentices turned again and again to the basic geometric forms, for example, using spheres for the body of a vessel and arcs for the armchairs, showing design diversity and dynamics (Figures 6 and 7). Furthermore, this villa reflects the Bauhaus design philosophy in terms of ergonomics, communications and aesthetic psychology, meeting human physical needs, behavior psychology and visual enjoyment.

In addition, Bauhaus tapered the space between arts and manufacturing [16]. It emphasized that architects should take responsibility to research and solve the contradiction between function and cost. The Dessau Bauhaus kept the record of lowest price at that time due to its simplicity, costing only twenty cents per square foot. This is a distinct example of pragmatism. Moreover, under Bauhaus's influence, modern architecture design becomes more and more beneficial. It maximises the

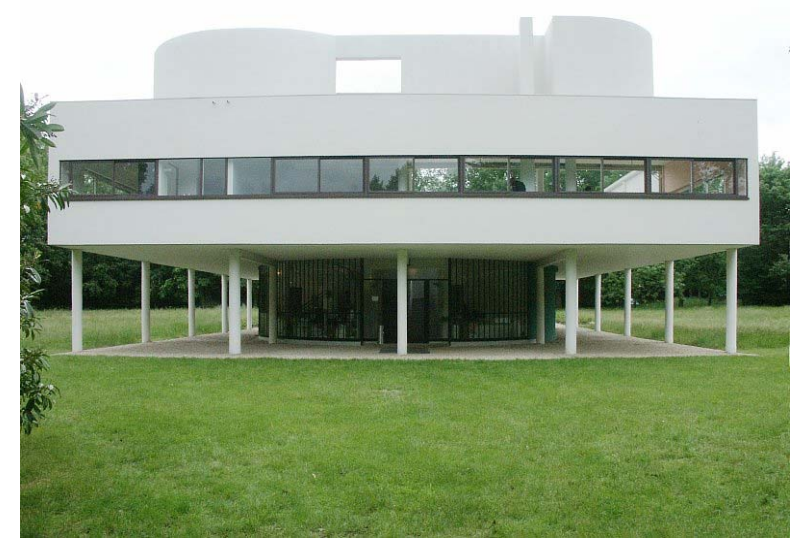

Figure 5. The Villa Savoye [13].

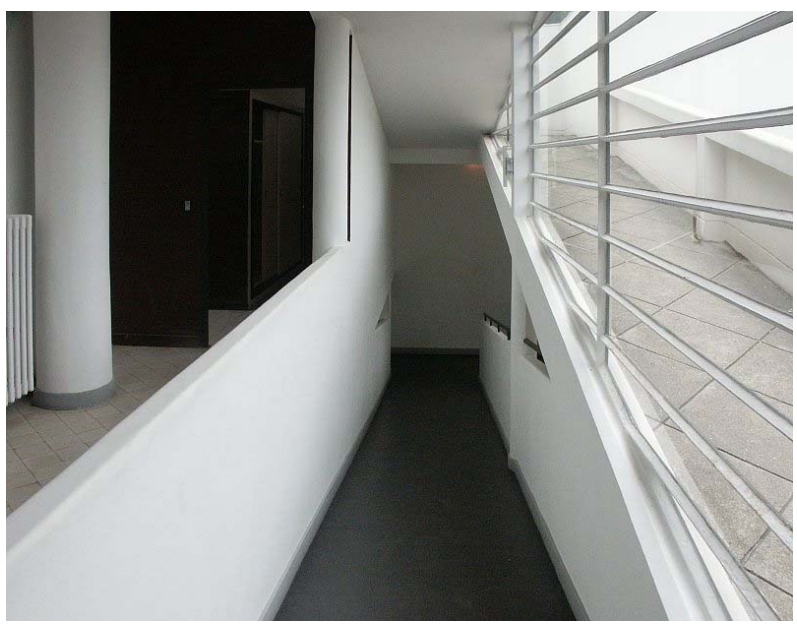

Figure 6. Views of the interior ramp [14].

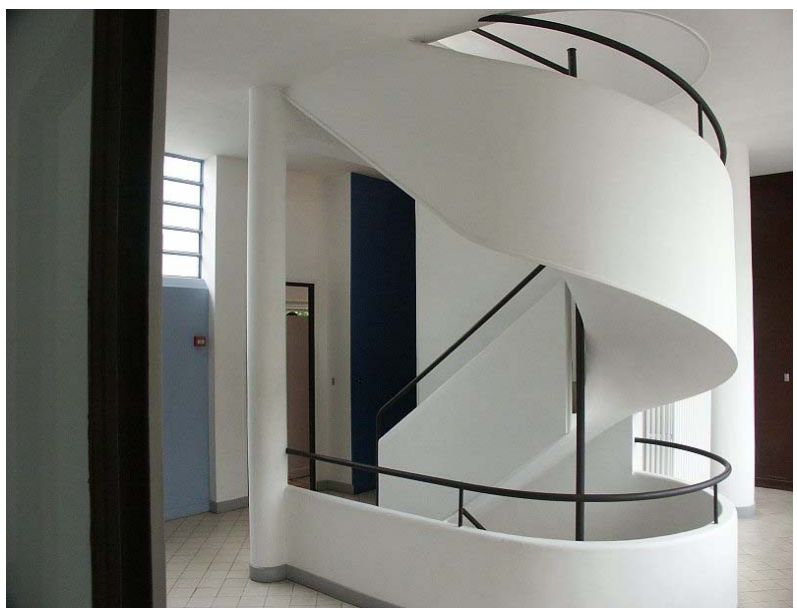

Figure 7. Views of the spiral staircase [15].

money's value, simultaneously, it breaks the traditional cliché design conceptions like heavy foundation and narrow windows, Le Corbusier's Villa Savoye would be one of the evidence.

Furthermore, modern architectures made long term adjustment to industrial age. "The Bauhaus strives to unite all creative activity within a single whole, to reunify all the practical artistic disciplines, as the inseparable components of a new architecture. The ultimate, if distant aim of the Bauhaus is the unified, total work of art - the great building - in which there are no distinctions between monumental and decorative art" [17]. Admittedly, developing aesthetics and encouraging new types of architectures are the basic characteristics of modernism.

\section{ART Education}

Bauhaus's main contributions and achievements in the field of Design and Education are listed as below: firstly, Bauhaus revolutionized the idea of "pure art" and "ap- 
plied art” as two mutually exclusive educational concepts, subsequently proposed the idealism of "group innovation". Gropius believes that "group innovation" is the core of design and this method benefits design and the development of industrial production. From construction to equipment, all necessary functions are included in the Bauhaus building. Therefore, this architectural design created an intimate community spirit, where teachers and students live in the same area and daily essentials are all provided in the dormitory, which enhanced the group morale and raised awareness on people's sense of compromise. In the process of teaching, allowing more opportunities to work in groups and set assignments that can be completed in groups in order to develop students' skills in communication and peer learning. Not long ago, Bauhaus-Luftfahrt machine "Claire" was born, it extended Bauhaus' group innovation idealism into the air (Figure 8). In appearance the plane employed the unique wing design, where wings, horizontal and vertical tails are fully integrated, improving the structural strength of the aircraft and its taking off and landing performance. The wings are connected at the head and tail of the aircraft, generating more internal space for the plane, which can be set as double deck cabin. There are two engines at the tail of the aircraft, which were placed in a small box structure that's preventing the high noise level as well as decreasing the fuel consumption. This project gathered 35 elites from the industry, in addition to the engineers and physicists, economists, computer specialists, georaphers, experts from culture and humanities as well as sociologists also participated in the research.

Secondly, through “factory apprenticeship”, Bauhaus emphasized on the combination of practice and theory to develop students' thinking, analytical skills and observation skills. Bauhaus focuses on the cultivation of sensory and abstraction abilities, as well as creativity. His teaching highlights first-hand experience. After 6 months of preparatory factory apprentice education, based on indi-

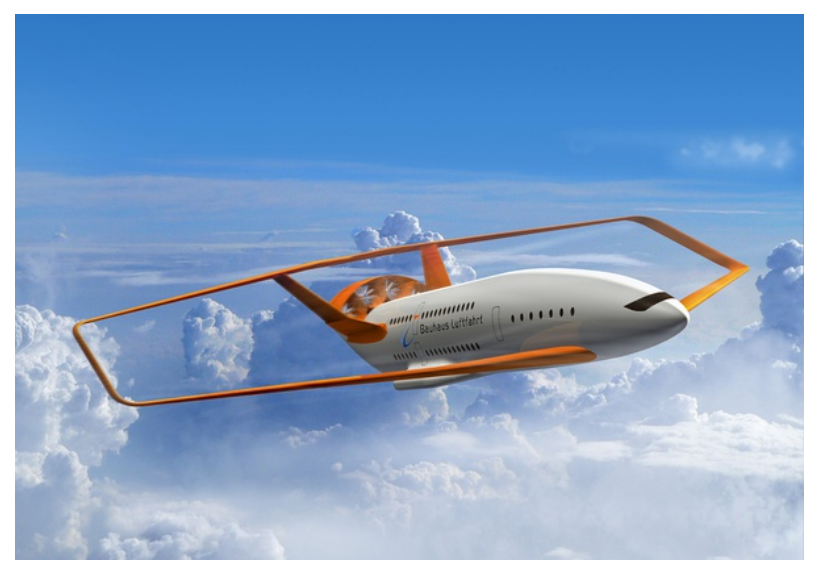

Figure 8. Bauhaus-Luftfahrt “Claire” [18]. vidual students' strength, they are assigned into different fields of design for a further 3-year apprenticeship education. Bauhaus encourages students to attempt a variety of workshops, try a diverse of materials and methods and through experiencing various experiments, explore more possibilities. He nurtures students to develop skills in finding problems and innovation to actively explore the creative and psychological orientation. As a student, Herbert Bayer once said when he was talking about Bauhaus' photography lessons, "In reality, we are not artists and photographers who create art consciously on purpose. We simply have an interest in the possibility of photography". Students would be more proactive and motivated in learning due to sufficient experiments and accumulated self-interest.

Besides, Bauhaus try to establish extensive contact with business, through the organization of many smallscale exhibitions, attracting enterprise to cooperate, which contributes the students to fully experience the link between design and production. Through the sculptors Gerhard Marcks and Master craftsman Max Krehan guidance, the apprentices from ceramics workshop learn design theory and practice at the same time. They participate in creating porcelain and ceramics production for the rural life all day long, and then put on the market to sell and also attain the reward. Walter Gropius puts forward that "I insisted on manual instruction not as an end in itself, or with any idea of turning it to incidental account by actually producing handicrafts, but as providing a good all-round training for hand and eye, and being a practical first step in mastering industrial processes” [19]. In this mode, students can achieve their ideas and artworks directly, but also get market feedback immediately, which do their optimization design gradually.

In addition, fine art is actually independent from imagination and artistic sense, emphasis needed to be placed on the process of understanding and practising. The course of Art Work Analysis is aimed at "developing keen observation skills on structure, space order, shape, rhythm and material by studying the techniques of ancient masters" so that students will be able to have an overall and correct understanding of the rules of visual performance rather than merely staying on the feeling of the artists as they did in the past. "The courses are designed by the following principles: 1) Technical drawing, taught with reference to each kind of craft activity; 2) The study of colour, applied to the various branches of the crafts; 3) The study of ornament, which following the law of dynamography and abstraction, provided the various branches of the crafts with ornament” [20]. From the course outline, it is presented to us explicitly that the Bauhaus students had the opportunities to receive design and art education, as well as gaining experiences and knowledge directly via workshops and courses. Their 
critical thinking and comprehensive skills were formed through the process of learning, which enable them to establish artworks with personalities and style.

\section{Conclusion}

In conclusion, although the Bauhaus was closed in the last century, its influence is still manifested in design industries now and will continue to spread its principles to designers and artists. To interweave arts and technology, seek culture identity, emphasize products' functionalities, explore multi-functional and high quality materials are design principles from Bauhaus. It also develops modern design theory on architecture design, industry design and crossover design. Alike, modern architecture contains ergonomics, communications and aesthetic psychology, which meets human physical needs, behavior psychology and visual enjoyment. The Bauhaus strives to unite all creative activity within a single whole, to reunify all the practical artistic disciplines, as the inseparable components of a new architecture. Bauhaus was a utopian world, it included team spirit, social equality and socialist ideal. It cultivates the students to enhancing their social responsibility and the rational the rational analytical skill of design. From the article, "Is the Bauhaus relevant today", Thomas Maldonado explained that "we are thinking of another Bauhaus, a Bauhaus that was often proclaimed but never realized, a Bauhaus which was unable to develop, which undertook, although unsuccessfully, to open up a humanistic view of a technological civilization, i.e. to see the human environment as a new 'concrete field for design activity'” [21]. Not only emphasizing function but also reflecting the human-oriented idea could be the greatest progress on modern design and manufacturing. Even more, harmonizing the relationship between nature and human is the ultimate goal for all the designers to create their artworks. Bauhaus is said to be the milestone to record the important achievement on modern architecture design, industry design history and art history.

\section{REFERENCES}

[1] “The Bauhaus and Its Influence,” 2003. http://www.spurensuchemidwest.org/a_Bauhaus_english. html
[2] F. Whitford, "The Bauhaus: Masters and Students by Themselves,” Conran Octopus, London, 1992.

[3] F. Whitford, "Bauhaus,” Thames \& Hudson Ltd., London, 1984.

[4] U. Muller, "Bauhaus Women: Art, Handicraft, Design," Flammarion, Paris, 2009.

[5] A. Rowland, "Bauhaus Source Book," Van Nostrand Reinhold, New York, 1990.

[6] T. Wolfe, "From Bauhaus to Our House,” Jonathan Cape Thirty Bedford Square London, London, 1981.

[7] L. Y. Zuo, "Bauhaus Style in the Wrist," 2012. http://www.vogue.com.cn/jewelry-watch/craft/news_103 g95ef34d03758.html

[8] U. Meyer, "Bauhaus,” Prestel, London, 2006.

[9] X. Zhao, “The Influence of the Bauhaus,” 2008. http://tech.163.com/06/0619/11/2JVO840T00091NE2.ht $\mathrm{ml}$

[10] W. Gropius, "The New Architecture and the Bauhaus," MIT Press, Massachusetts, 1965.

[11] “National Gallery Building: Architecture,” 2008. http://www.e-architect.co.uk/berlin/national_gallery_buil ding.html

[12] E. Weinel, “50’s Minimalism,” 2008. http://www.ou.edu/class/arch4443/50's\%20Minimalism/5 0Minimalism.html

[13] M. A. Sullivan, "Views of the Northwest Facade and Main Entrance," 2008.

http://www.bluffton.edu/ sullivanm/france/poissy/savoye 10130.jpg

[14] M. A. Sullivan, "Views of the Interior Ramp,” 2008. http://www.bluffton.edu/ sullivanm/france/poissy/savoye /0049.jpg

[15] M. A. Sullivan, "Views of the Vestibule and Stairwell," 2008.

http://www.bluffton.edu/ sullivanm/france/poissy/savoye /0047.jpg

[16] “The Bauhaus,” 2008. http://www.designhistory.org/Bauhaus3.html

[17] F. Whitford, “Bauhaus,” Thames \& Hudson Ltd., London, 1984.

[18] F. Fire, "Bauhaus-Luftfahrt," 2012. http://www.douban.com/note/163574484/

[19] M. Droste, “Bauhaus,” Taschen, Cologne, 2006.

[20] F. Whitford, "The Bauhaus: Masters and Students by Themselves,” Conran Octopus, London, 1992.

[21] J. Fiedler, “Bauhaus,” Ullmann Publishing, Berlin, 2008. 